\title{
DEMAND FORECASTING AND DEMAND SUPPLY MANAGEMENT OF VEGETABLES IN INDIA: A REVIEW AND PROSPECT
}

\author{
A.Srinivasa Reddy ${ }^{1}$, P. Chakradhar², P.Pavan Kumar ${ }^{3}$, Tejasantosh ${ }^{4}$ \\ ${ }^{1}$ Assistant professor, GITAM, Hyderabad, Telangana, India \\ ${ }^{2}$ Assistant professor, GITAM, Hyderabad, Telangana, India \\ ${ }^{3}$ Assistant professor, Faculty of Science and Technology,IFHE, Hyderabad, Telangana, India \\ ${ }^{4}$ Assistant professor, GITAM, Hyderabad, Telangana, India
}

\begin{abstract}
Vegetable quantity arrival to market varies every day with which its prices also changes rapidly. This paper analyses the factors that affect the rapid change in prices of vegetables such as demand forecasting, demand supply management, erroneous statistics of vegetables, storage facilities, and supply chain system, etc. Government of India has no control over the production of horticultural and agricultural crops, sometimes under produced and sometimes over produced, which makes demand supply management hard-won. This paper mainly focuses on advantages of demand forecasting and demand supply management of vegetable crops and their effects on farmers and consumers. The Government should find a novel method or a system which gets crop data from farmer, does demand forecasting on day to day basis, control crop acreages, generate accurate statistics and do demand supply management of crops.
\end{abstract}

\section{Keywords:}

Crop Acreage Control; Demand Forecasting; Demand Supply Management; Vegetable Statistics; Support Price

\section{INTRODUCTION}

India is a country which grows major varieties of vegetables due to its diverse climate. India ranked $2^{\text {nd }}$ in the world in fruits and vegetable production after China. It produced 283 million tons of fruits and vegetables during the year 2015-16. Horticultural crops output has a share of over 33 percentage in total agriculture output. There was a significant increase in the production of horticultural crops due to increase in demand. Horticultural crop acreage increased by $18 \%$ when compared with food grain crop acreage increase by $5 \%$ over the past few years (1).Table-1 shows an increase in vegetable production over the past years (2). Horticulture crops bring a lot of income to the farmers in less time and effort, and also add nutrients to our food. The production of vegetables increases every year to meet the required demand of the people in the country. Vegetables demand graph is increasing steadily but supply graph is fluctuating in India. The Indian vegetable market is facing a massive problem of rapid fluctuations of prices. Figure- 1 a shows the daily price of tomato in Hyderabad vegetable market, Hyderabad for the years 2015,2016 (3).The factors that influence this are lack of demand forecasting, demand supply management, improper statistics, cold storage system, weather conditions, rainfall, ground water availability, etc. Among these factors some are controllable and some are uncontrollable. The uncontrollable factors being weather, rainfall and availability of ground water (4).

\section{PROBLEMS FACING BY VEGETABLE FARMERS AND CONSUMERS}

Farmers who are farming vegetables crops are facing lot of problems like support price for their crop, crop yield, marketing facilities, weather conditions, pest control etc. This paper mainly focuses on support price. There are a lot of factors that affect the support prices of vegetables; it is mainly affected by demand supply management. Farmers do not know how much demand and supply is there in the market for a particular type 
of vegetable because they do not have demand forecasting, so they start farming the vegetable crop of their own choice randomly.

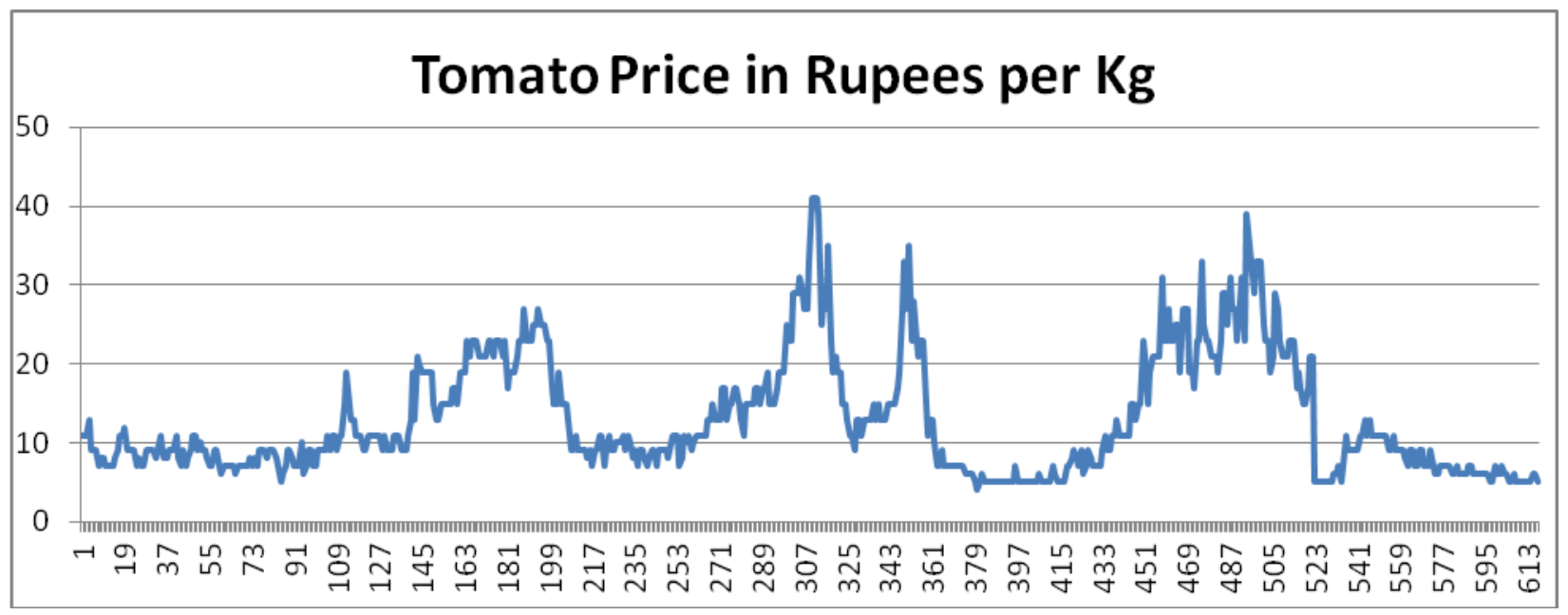

Figure 1a Daily consumer price (Rs) of tomatoes in Hyderabad for the years 2015, 2016

Table 1 Year wise Crop area and Production in India

Also, farmers do not know how much quantity of vegetables to be produced to meet the demand, Due to this most of the time there is no balance in demand and supply. If more number of farmers producing same type of vegetable its support price will go low and farmers will be in loss, on the other side if less number of farmers are producing the same type of vegetable crop, its prices goes high, farmers will get profit and consumers cannot afford high prices of vegetables. So if there is no proper demand supply management either the farmer or the consumer will be in loss. Farmers are investing a lot of money, hard work and time in vegetable crops production, but they are getting huge losses when they try to sell their product

Year Area[Hectares]

Production[1000 Tonnes]

2009-10

8011

134102

2010-11 8484

146554

2011-12 8989

156325

2012-13 9205

162189

2013-14 9396

162897

2014-15 9494

167058 in the market. Some farmers are destroying their own crops due to less support prices (TOI, 2016a). On the other side when the supply is low consumers are not able to buy the vegetables which affects their food diet. Vegetables are perishable in nature; they cannot be stored for a long time. There is no sufficient number of cold storage available to store all those produced vegetables. Most of the rural places do not have any cold storage to store vegetables (4), even if farmer store them for some time, there is no guarantee that he will get good prices. To accommodate all the excess produced vegetables, Government of India needs a large number of cold storage which is very expensive (5). If vegetables are less produced than required, then prices go high and this is a problem for the consumer, Note that farmers cannot speedup the production of agricultural goods, they need a fixed amount of time to harvest. So government need to import vegetables from other countries to meet the demand.

\section{SITUATION IN DEVELOPED COUNTRIES AND IN INDIA}

Presently in developed countries like The United States of America crop area estimates are done by using remote sensing; remote sensing is a technology with which one can collect the information about an objects or crop area without being in direct contact with the objects or crop area. Aircraft and satellites are the most common vehicles from which remote sensing observations are made. These vehicles are equipped with high quality cameras to take aerial photography of crop area. These aerial photographs are used to prepare data like crop area estimation, crop harvesting dates, the total quantity of vegetables arrive to market, etc in 
advance. Apart from these there are good storage facilities, demand supply management, marketing, transportation and packing facilities are available (Craig, M. \& Atkinson, D., 2013). Due to these reasons there is a better demand supply management of vegetables is present in the USA than in India. The graph below shows in figure 1 shows Consumer Price Index for All Urban Consumers: Fruits and vegetables, Percent Change from Year Ago, Monthly, and Seasonally adjusted.

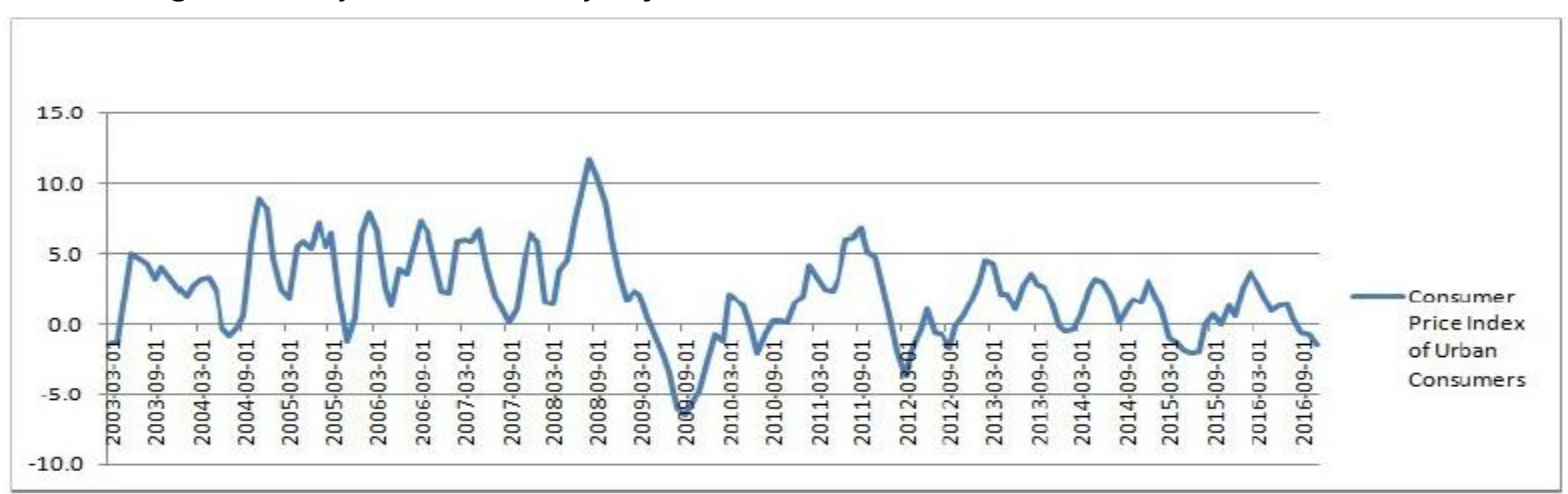

Figure 1b Consumer Price Index for All Urban Consumers: Fruits and vegetables, Percent Change from Year Ago, USA

In India, the scenario of vegetable demand supply management is worse, farmers do not have a working model to do demand forecasting of vegetables and demand supply management (7); due to this vegetable prices fluctuate enormously within a short period of time. Figure 2 below shows change in price of tomato in Telangana state for the years 2014-15, 2015-16 (3).From above two graphs, it is clear that vegetable prices vary rapidly and severely in India. In the month of April, 2016, the price of tomato increased by $150 \%$ when compared to the previous year.

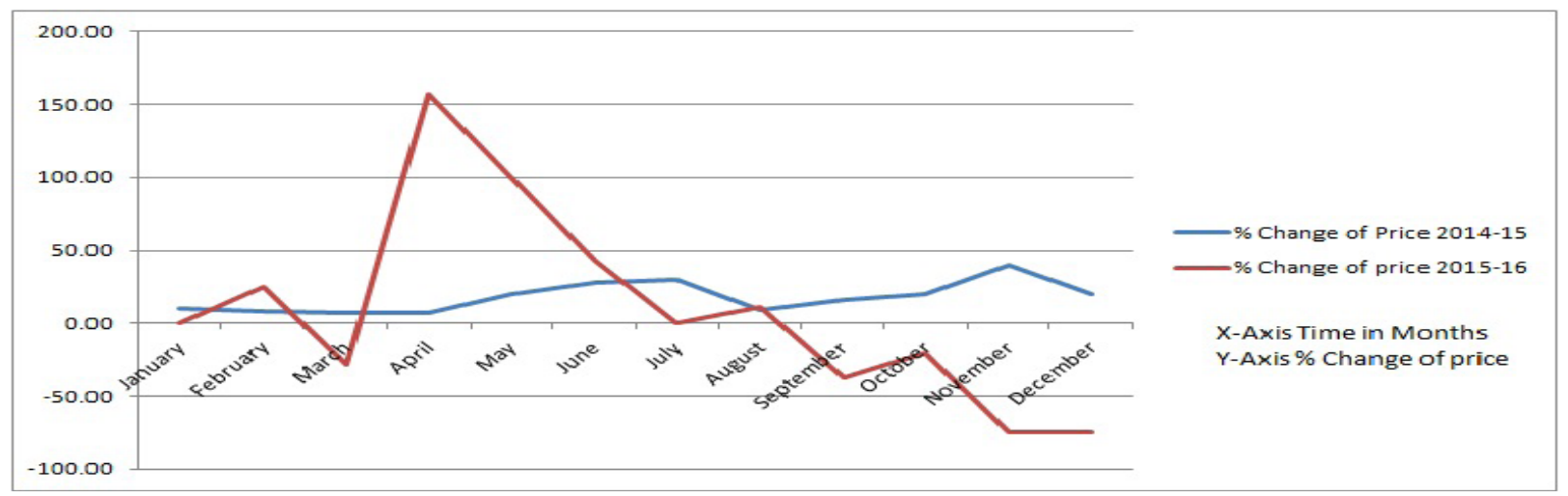

Figure 2 Change in price of tomato in Telangana State for the years 2014-15, 2015-16.

\section{FACTORS THAT AFFECT PRICE FLUCTUATIONS}

Pricing of vegetables is complex because vegetables are perishable in nature; they cannot be stored for a long period of time. Quantity of vegetables arrived to market varies every day; due to this prices also vary. A Lot of factors that affect the quantity of vegetables arrived to the market. Following are some of the factors that affect the prices of vegetables.

\subsection{Demand Supply Management (DSM)}

This is the most important factor that affects the prices of vegetables. They can be grown throughout the year and they are consumed throughout the year; Demand basically depends on population growth rate, income elasticity, The UN's Food and Agriculture Organization (Ganesh-Kumar et al., 2012). It is calculated by using the formula as shown below. 


$$
S_{i}=\alpha_{i}+\sum_{j} \beta_{i j} \ln F P_{i}+\gamma\left(\frac{\ln P C}{G I}\right)+\mu A
$$

where $F P_{i}$ is the price of $i^{\text {th }}$ agriculture items and groups,

$P C$ is per capita food consumption,

$\mathrm{Gl}$ is the Stone geometric price index,

$A$ is a variable depends on various factors,

$\alpha_{i}, \beta_{i j}, \mu, \gamma$ are model parameters.

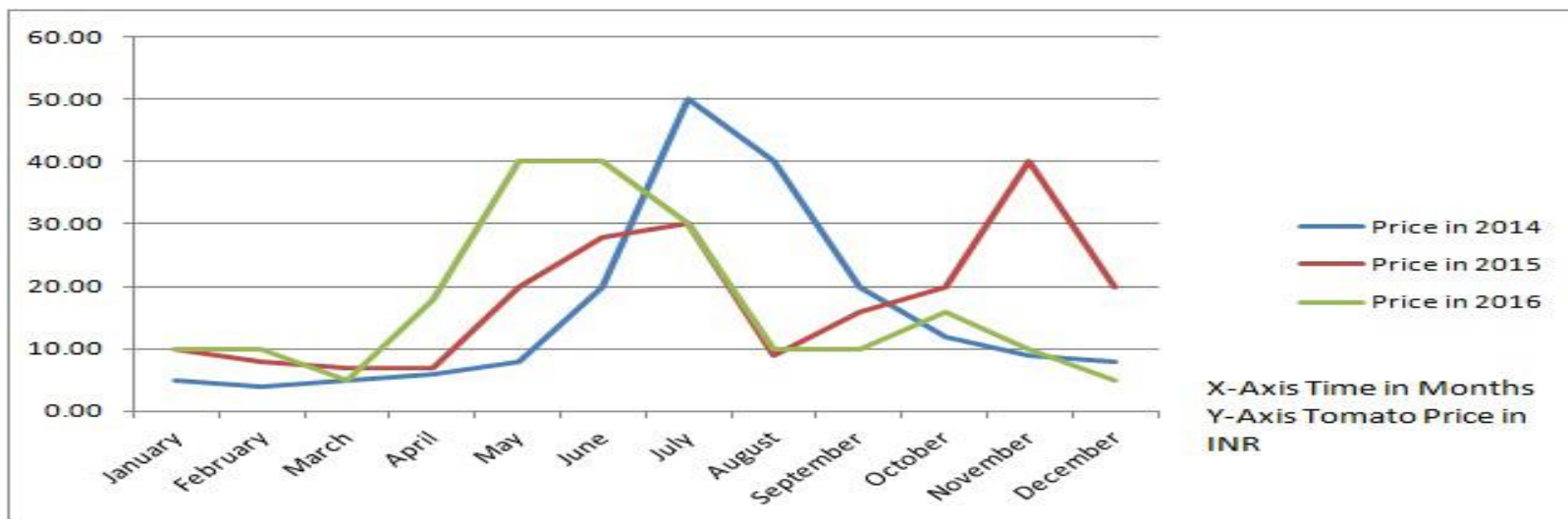

Figure 3 Monthly variations in prices of tomato in Telangana State for the years 2014-17

\subsection{Demand Forecasting}

Demand forecasting is another important factor that determines the supply of vegetables to market. Demand should be calculated and forecast to farmers regularly so that farmers can supply vegetables to market according to demand. In India, there is no practical demand forecasting methods for vegetables $(7,8,10)$, this is the reason most of the times demand and supply are not matching and loss to farmers and consumers. Since vegetables crops are short duration crops and farmed in small areas in large number, the statistical methods that estimates the crop area, yield, market arrival dates will not work for vegetable crops. Since there is no demand forecasting, farmers by their choice farms particular vegetable crop bases on previous year prices. Every farmer thinks in a similar way and a large number of farmers farm same vegetable crop with which supply increases and demand decreases. Farmers actually do not know demand, supply and how many other farmers are farming the same crop at the same time. Supply of vegetables must be equal to the demand to bring stability in the market. Factors that affect the supply of vegetables to market are vegetable demand (price), crop area, crop yield, weather conditions, Marketing facilities, transportation, transparency in pricing etc (7). Among these the most important factor that determines the supply is demand, Demand pulls the supply of vegetables to market irrespective to other factors, and if supply increases demand drops down viceversa. Demand and the supply are inversely proportional to each other. There must be supply of vegetables to market equal to demand.

\subsection{Vegetable Statistics}

Farmers need vegetables crops which are in demand before they sow the seeds. The Indian horticultural department maintains vegetable data like the amount of vegetables had arrive the market, prices of each vegetable, market wise, district wise and the state wise of each day (7). The government is able to get statistics after vegetables arrived the market, which does not favour to the farmer because he cannot store all the excess vegetables if the prices are low. We have no storage facilities for vegetables and farmer is forced to sell his product at low prices. The conventional method of preparing statistics by complete enumerate for vegetables is very difficult.

\subsection{Improper storage facilities}

According to The UN's Food and Agriculture Organization, every year 40\% of India's fresh fruits and vegetables worth $\$ 8.3$ billion perish before reaching consumers (12). This is despite the fact that India is the 
Volume: 17 Issue: 1

International Journal of Computers \& Technology

second largest producer of fruits and vegetables, producing around 83 million tonnes of fruits and 121 million tonnes of vegetables annually. In fact, only two per cent of produce in India are held or transported using cold storage facilities compared to 85 per cent in the US with an ensuing gap between supply and demand coming to 25 million tonnes. Every year $40 \%$ of vegetables is wasted due to post harvest management. The cold storage facility is an important factor that affects post harvest management. India needs a large number of cold storage to minimize post harvest losses (Sivaraman, M., 2016). There are a lot of challenges involved like cost of construction, Power supply, lack of infrastructure, skilled labour, maintenance, awareness among the farmers etc. It takes lot of time and money to construct a large number of cold storage. The Most important thing to note is that farmers have no idea that for how many days he has to store the crop to get support price.

\subsection{Marketing, Transport, Packing facilities}

Marketing of vegetables is complex due to perishable nature. Prices rapidly changes due to improper demand supply management. Price completely depends on the amount of vegetables come to market. Different types of marketing methods are present in India $(7,17,5)$.Each of these have its own advantages and disadvantages, there is no centralized body that controls vegetable prices, on a same day in the same market from trader to trader the price of vegetables varies. Traders, wholesalers and shopkeepers become a syndicate and reduce the prices of vegetables. Transport of vegetables to market is also very important. In India most of the villages do not have good transport to carry vegetables directly to market; they have to change the means of transport multiple times to reach the market due to which some of the vegetables get damaged and transportation price also increases. The toughest part of transport is farmers have to carry their vegetables on their head from crop field to road where he can board the goods into a vehicle. Most of the time vegetables are transported to those market places where demand is more, this increases transportation cost $(6,8,9)$.Effective packing methods are not used by the farmers because they are costly and lack of knowledge, due to which some of the vegetables get damaged during transportation.

\subsection{Weather Condition}

India has diverse climatic conditions which make it to grow most of the vegetable types (14). Climate plays an important role in crop yield, vegetables can be grown in any season but yield varies by season, an example of such kind is tomato which grows throughout the year but yield varies from season to season. In summer tomato yield is low due to high temperatures, but from December to mid of March yields are high. In rainy season due to heavy rains and in summer season due to temperature, large crop areas were damaged due to the blossom dropping (Flowers falling). Vegetable prices largely affected by seasonal variations due to yield variations. Farmers can improve vegetable yield irrespective of seasons by using ploy house shade nets and sheds. In India only few farmers were using poly house shade nets because of high cost and even if he grow vegetables in poly house shade nets, there is no guaranty that he will get good returns because no demand forecasting for vegetables in India. Below figure shows variation of market arrivals of tomato, month wise for the years 2012-2016

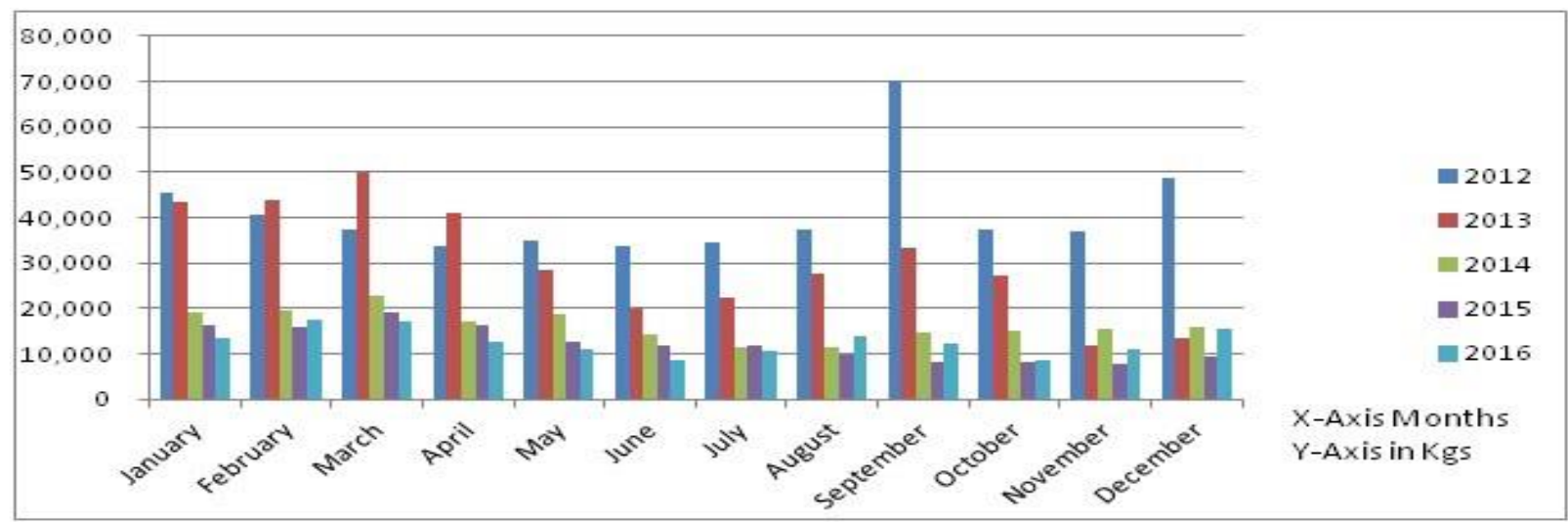

Figure 4 Variation of market arrivals of tomato in Telangana State, month wise for the years 2012-2016 


\subsection{Rainfall and Ground water Availability}

Almost $50 \%$ of the crops in India is rainfall dependent. If we have good rainfall ground water increases, and there will be a sufficient amount of water in rivers, canals, wells and tube wells. Vegetables are normally farmed where there is an availability of water. If ground water is available large number of farmers grows vegetables and supply increases and demand decreases. So there is direct relation among rainfall, groundwater and vegetable productivity.

\subsection{Supply chain management (SCM)}

Supply Chain Management deals with the flow of vegetables from farmers to traders, wholesalers, and retail shops and to consumers $(4,5,7)$. SCM is complex for perishable goods like vegetables. There are a lot of concerns in SCM like cold storage, transport, pricing, packing, and infrastructure issues (Bao, L. \& Wang, J., 2008) .The people in SCM like traders, wholesalers play a vital role in fixing prices of vegetables. Sometimes they regulate the demand and vary the price according to their needs, which makes the farmer in loss. There is a lot of scope to improve SCM of vegetables in India. The Government has to take active measures to improve SCM.

\subsection{Fake Seeds}

Fake seed issues are mostly present in the agricultural sector when compared with horticulture. All seed packet manufacturer should test their seeds in an authorized laboratory and should get certified; instead fake seed packets were dumped in to the market $(5,16)$. Farmers usually trust the shopkeeper, so they sell this fake seeds to farmers and farmers are not in a position to detect this fake seed packet. Farmers find the fake seed only when crop comes to flowering stage, by this time all the input to the crops had been spent for which he will not get anything back. Due to these fake seeds farmers are in huge loss, forcing them to commit suicide. Government has to take necessary action to eructate fake seeds by not allowing them to enter in to the market or there should be a easy way to find fake seed packet before they sow the seeds.

\section{FACTORS THAT CAN BE CONTROLLED}

Factors that are controlled by government are Demand supply management, Demand forecasting, Preparation of statistics, Storage facilities, Marketing, Transport, Packing facilities, Fake seeds.

\subsection{Demand forecasting}

There should be a novel system or method with which demand forecasting should be done by the government on day to day basis for each and every vegetable (Agricultural Statistics). Farmers will farm only those vegetable for which the demand is present.

\subsection{Demand Supply Management}

DSM is maintained by calculating demand on day to day basis for whole year in advance and let farmers know the demand, so that farmers can supply vegetables according to the demand of the consumers. Vegetables demand mostly depends on population and supply depends on crop acreage. By controlling crop acreage we can control vegetables supply.

\subsection{Preparation of statistics}

It is very difficult to prepare statistics for vegetables crops which are short in time duration, farmed in small areas and in large number. Advanced methods should be introduced by which vegetable statistics are prepared on day to day basis, so that demand forecasting can be done.

\subsection{Storage facilities}

In India only $2 \%$ to $4 \%$ of produced vegetables are stored in cold storage. To store the extra produced vegetables, the government need large number of cold storage (5). When demand and supply of vegetables are balanced, there is no need to store vegetables. With few cold storage installed at various places the government can control the supply of vegetables.

\subsection{Marketing, Transport \& Packing}

When demand and the supply are balanced, then prices will be stable, vegetable market will be more transparent, farmers will get support prices. Even government can fix the price of each vegetable based on its farming cost. When the cost of vegetables is same everywhere, farmer is not required to go long distance to sell his crop for better prices, with which transportation charges reduces. If farmer is getting good returns he 
can now focus on how to reduce the vegetables damage during transportation. Also farmer may adopt advanced methods of packing which reduces damage; because he knows that it increases his returns.

\section{FACTORS THAT CANNOT BE CONTROLLED}

Factors like Weather conditions, Rain fall, Ground Water level, nature disasters cannot be controlled or avoided by human beings, but its effect can be reduced by various methods like poly house sheds and nets. Since these methods of farming are costly farmers are not interested. Even if they farm in the poly house there is no guarantee that they will get the support price for their crops. Most of the farmers do not have knowledge about these latest farming techniques, they follow the traditional way of farming. If demand and supply is maintained, farmers will get good returns, when they get good returns then they try to increase their yield by adopting poly house sheds and nets. The Supply of vegetables should be calculated based on acreage, seasons, weather conditions, type of soil, seed variety, etc. The only controllable factor which will control the supply of vegetables to market is crop acreage. Government should forecast crop demand for each and every crop to the farmers, and get crop data like crop type, crop acreage, seed sowing date; crop location, etc time to time from the farmer using latest communication technologies, then the updated demand should be communicated to the farmers, by which crop acreage can be controlled and demand supply management can be balanced as shown below.

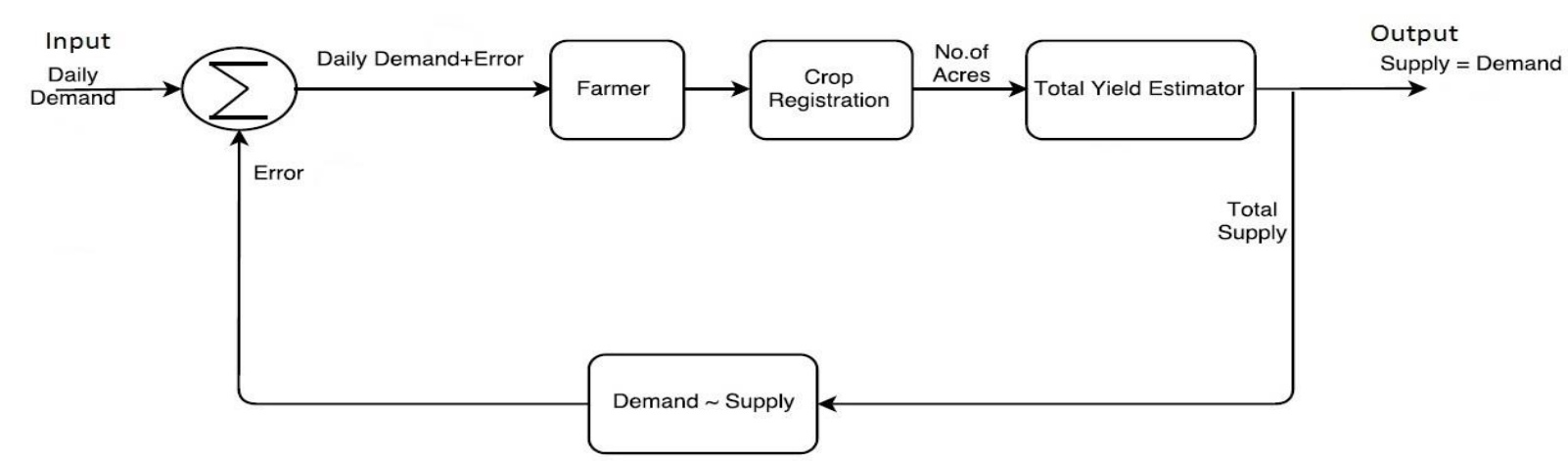

Figure 5 Crop demand forecasting and crop data feedback system

\section{EXISTING METHODS TO PREPARE STATISTICS}

The government of India started a scheme plan called Crop Estimation Survey of Fruits and Vegetables to improve the agricultural statistics in India. This was implemented by Directorate of Economics \& Statistics of the Ministry of Agriculture and Farmers Welfare. This scheme features the preparation of crop area and productivity estimates using sampling and estimation methodology derived by Indian Agricultural Statistics Research Institute. National Statistical Commission however found some problems with this scheme and also recommended to find other methods to prepare crop area estimates which can be tried out on pilot basis before actually implementing it on a large scale $(7,11,12,13)$ IASRI has developed an alternate methodology called Coordinated Programme on Horticulture Assessment and Management using Geo-informatics with which crop area estimates can be prepared simpler and easier. National Statistical Commission reviewed this method and recommended to implement on pilot basis. This project is now implemented in 6 states by Department of Agriculture Cooperation \& Farmers Welfare. The main objective of this project is to use advances methodologies to estimate crop area and crop yield of both agricultural and horticultural crops. It uses advanced methods like remote sensing technology and sample survey methodology $(7,14,15,16)$.

\section{LIMITATIONS \& CHALLENGES OF EXISTING METHODS}

National Statistical Commission has identified the following major flaws in the scheme because horticultural crops are short duration crops, farmed in small areas by large number of farmers. CES-F\&V should be reviewed, and an alternative methodology for estimating the production of horticultural crops should be developed, taking into account information flowing from all sources including market arrivals, exports and growers associations (Agricultural Statistics). 
DESMOA prepared a methodology and implemented on pilot scheme based on sound technology to prepare the production estimates of fruits and vegetables. This is based on survey method so it was found that it is very complex in nature, require long time rather very difficult to implement in practice. This method is limited to only 11 states further it takes a long time to extend to remaining states. It requires large number of field staff to take information about the crop directly from farmers in the field. It is very difficult to implement this scheme throughout India. The estimates prepared by NHB on horticultural crops are not reliable because the ground staff does not do proper survey. It is observed that the field staff does not always follow the procedures laid down for collection of data (7). The new method developed by the IASRI called Coordinated Programme on Horticulture Assessment and Management using Geo-informatics Project still have issues like crop discrimination within vegetable crops, yield modeling and stress detection. This method cannot do demand forecasting or balance demand and supply of vegetables. It is used to prepare statistics, and can predict amount of supply of fruits and vegetables to some extent. Still this project is not implemented throughout India. Advanced methods should be developed to carryout demand forecasting and demand supply management and to prepare accurate statistics in a short duration of time.

\section{ADVANTAGES OF DEMAND FORECASTING AND DEMAND SUPPLY MANAGEMENT}

Demand forecasting plays a vital role in supply chain management. The supply of vegetables mostly depends on demand, if the government could calculate the demand in advance and forecast to the farmers then farmers will grow the crops according to the demand, by which farmers get good returns and consumers also will be benefited due to increase in supply and price will decrease. The most challenging part of demand supply management is to control the supply according to demand. Since government does not have statistics about crop acreage, vegetable varieties ready to supply to market, etc, it cannot control the supply. If government could forecast the demand on day to day basis, and control the supply of vegetables to market according to demand, then it can solve most of the farmer problems like Supply chain management, Demand Supply Management, Support Price, Cold Storage Infrastructure, Food Wastage and Food Security, Transportation Cost, Inflation, etc.

\section{CONCLUSION \& RECOMMENDATION}

This paper concludes with the major point being stressed that the farmers are facing a lot of problems due to imbalance in demand and supply of vegetables. They do not get demand forecasting, support prices, storage facilities, marketing facilities, etc across India. Vegetable supply to the market is uncontrolled, with which prices will get fluctuated enormously. This paper recommends to establishing a system or method, with which demand forecasting of vegetables is done on day to day basis, also should control the supply of vegetables to market according to demand, since supply of vegetables depends on acreage, season, rainfall, ground water level, demand etc. Demand is calculated as mentioned in section 4.1; supply mainly depends on acreage, season, rainfall, soil type and ground water etc. The only controlled factor that determines supply of vegetables to market is crop acreage. So if government can control the number of acres a particular vegetable should be farmed everyday to maintain supply equal to demand, then most of the above mentioned problem can be solved. There are many advanced technologies like USSD/IVR communication systems, Internet of Things, Information Technology by which government can get crop data directly from farmer instantly.

\section{REFERENCES}

[1] Economic Survey 2015-16: Percentage Share of Horticulture Output in Agriculture is more than 33 Percent. http://pib.nic.in/newsite/printrelease.aspx?relid=136852

[2] NHB-2015: National Horticultural Board, http://nhb.gov.in/PDFViwer.aspx?enc=3Z008K5CzcdC/Yq6HcdlxCOU1kZZenFuNVXacDLxz28= [3] _Trbis: Telangana Rythu Bazar Information System year 2017, http://183.82.114.68/rbzts/VegwiseReport.aspx

[4] Saurav Negi and Neeraj Anand (2015). Issues And Challenges In The Supply Chain Of Fruits \& Vegetables Sector In India: A Review,IJMVSC, Vol. 6, No. 2. 
[5] Times of India 2016:70\% vegetables going waste, prices nose-dive, http://timesofindia.indiatimes.com/city/lucknow/70-vegetables-going-waste-prices-nosedive/articleshow/55863243.cms

[6] The Hindubusinessline:India needs to expand cold storage facilities, http://www.thehindubusinessline.com/economy/agri-business/india-needs-to-expand-coldstorage-facilities/article6654824.ece

[7] Rais M, Sheoran A, 2015, Scope of Supply Chain Management in Fruits and Vegetables in India. J Food Process Technol,Vol 6,Issue 3.doi:10.4172/2157-7110.1000427

[8] Michael Craig, Dale Atkinson 2013 \& A Literature Review of Crop Area Estimation, Food and Agriculture Organization, United Nations Organization

[9] Ganesh Kumar, Rahesh et al 2012, IFPRI discussion paper 01158, Demand and Supply of cereals in India 2010-2025,Environment and Production Technology, New Delhi.

[10] Srikanth, Sankaran, 2014 _ Demand forecasting of fresh vegetable product by seasonal ARIMA ,Int. J. Operational Research, Vol. 20, No. 3.

[11] Horticultural statistics at a glance-2015, Horticultural statistics at a glance-2015, Horticulture Statistics Division, Department of Agriculture, Cooperation \& Farmers Welfare, Ministry of Agriculture \& Farmers Welfare, Government of India [12] Financial Times 2014, India tackles supply chain to cut food waste, https://www.ft.com/content/c1f2856e-a518-11e3-8988-00144feab7de

[13] Madhu Sivaraman, 2016,_Government's Role in India's Ailing Cold Storage Sector, Dec-2016, https://www.researchgate.net/publication/311438935 Government\%27s Role in India\%27s Ailin g Cold Storage Sector

[14] Agriculture in India, Natural Environment, Resources and Development, http://www.nos.org/media/documents/316courseE/ch20.pdf

[15] Liwei Baa,(2008),Jinping Wang, Study on the Management and Reengineering of Supply Chain of Vegetable Circulation

[16] Fake seeds menace sprouts in Mahbubnagar.Times of india, http://timesofindia.indiatimes.com/city/hyderabad/Fake-seeds-menace-sprouts-in-

Mahbubnagar/articleshow/47316224.cms

[17] Agricultural Statistics, http://mospiold.nic.in/Mospi_New/upload/as_4.html[18] The Hindustan Business Line, India needs to expand cold storage facilities, http://www.thehindubusinessline.com/economy/agri-business/india-needs-to-expand-cold-storagefacilities/article6654824.ece 